\section{Aspectos culturais na compreensão da periodontite crônica: um estudo qualitativo}

\author{
Cultural aspects in the understanding of \\ chronic periodontitis: a qualitative study
}

\section{${ }_{1}$ Universidade de Fortaleza, Fortaleza, Brasil. \\ 2 Harvard Medical School, Boston, U.S.A. \\ 3 Universidade Federal do Rio Grande do Norte, Natal, Brasil. \\ Correspondência S. A. S. Nuto Universidade de Fortaleza. Rua Marlio Fernandes 81, apto. 503/C, Fortaleza, CE 60811-370, Brasil. nuto@unifor.br}

\section{Abstract}

This study aimed to analyze the concepts, beliefs, attitudes, and explanatory models related to chronic periodontitis among individuals with this disease in order to facilitate communications between dentists and patients and foster conscientious treatment adherence. The study sample consisted of 20 patients from the Periodontics Specialization Courses at Fortaleza University and the Brazilian Dental Association in Fortaleza, Ceará State. Data were gathered from October 2004 to January 2005. A qualitative methodological framework was used to interpret the patients' subjective expression. Semistructured interviews were applied to obtain patients' accounts of their individual experience with the disease condition. Thematic discourse analysis used: empirical categories established within the study itself, simple frequencies and calculated percentages, and refinement of thematic classifications. According to their reports, patients understand the periodontal heath-disease process through the intermediation of both popular and scientific knowledge, involvement of living and work conditions, and access to quality care, i.e., they do not incorporate only the biomedical discourse.

Periodontitis; Self Care; Health Education; Qualitative Research
Sharmênia de Araújo Soares Nuto ${ }^{1}$

Marilyn Kay Nations 1,2

Íris do Céu Clara Costa 3

\section{Introdução}

Muitos estudiosos da área da Antropologia Médica têm pesquisado as dificuldades de comunicação clínica entre profissionais de saúde e pacientes $1,2,3$. Isso se deve aos diferentes modelos explicativos de uma mesma enfermidade. Kleinman ${ }^{4}$ define modelos explicativos como o conjunto de idéias de todos os envolvidos no processo clínico, o qual é sustentado pelos pacientes e pelos médicos, e oferece explicações sobre as doenças e seus tratamentos.

Esses modelos explicativos médicos e populares, muitas vezes, divergem, resultando em grandes dificuldades de comunicação clínica. Isso ocorre porque os modelos médicos são respaldados pela ciência moderna, por meio de pesquisas, e os modelos populares são idiossincrásicos, mutáveis e fortemente influenciados pela personalidade e por fatores culturais 4,5 .

A consulta clínica é o momento de transição entre os modelos explicativos, leigo e profissional. No primeiro momento, é realizada a apresentação da doença pelo paciente, de forma verbal ou não-verbal, a qual inclui as dimensões psicológicas, morais, sociais e espirituais. Em seguida, o profissional, de acordo com o conhecimento científico, faz a tradução do quadro apresentado pelo paciente em sinais fisiologicamente e patologicamente quantificáveis para que eles adquiriram significados de doença. E no momento final, na indicação do tratamento, é realizada 
uma negociação entre as partes, em que tanto as metáforas dos pacientes são incorporadas pelo vocabulário médico, como a fala popular é influenciada pelo discurso científico 5,6.

Mas em última instância, prevalece o modelo dos profissionais de saúde, não havendo uma influência significativa do saber popular na construção do processo terapêutico 7. Para colaborar na compreensão dos modelos explicativos em Odontologia, este estudo foi realizado utilizando-se a análise das concepções, das crenças e das atitudes dos pacientes portadores de periodontite crônica.

O termo doença crônica é conceituado como qualquer estado patológico que apresente uma ou mais das seguintes características: que seja permanente, que deixe incapacidades residuais, que produza alterações patológicas não reversíveis, que requeira reabilitação ou que necessite de períodos longos de observação, controle e cuidados. Além disso, são resultados de processos mórbidos de variada etiologia, que por sua relativa freqüência e severidade possuem grande importância médica, social e econômica para a sociedade 8 .

As periodontites crônicas são inflamações crônicas e progressivas, caracterizadas clinicamente por inflamação gengival, sangramento à sondagem, diminuição da resistência dos tecidos periodontais à sondagem (bolsas periodontais), perda de inserção gengival e do osso alveolar. As características variáveis incluem hiperplasia ou recessão gengival, exposição da furca, mobilidade e inclinação dentárias aumentadas e esfoliação dos dentes. E possuem como etiologia primária a presença de bactérias específicas residentes no biofilme dentário, associada à deficiência no mecanismo de defesa do paciente 9,10.

Essas periodontites crônicas têm início como uma gengivite logo após a puberdade, mas como a progressão é lenta, os sintomas como a perda óssea e a inserção só serão observados posteriormente. Por isso, a idade não é considerada um fator de risco, mas uma conseqüência dos efeitos acumulados durante os anos 10 . A progressão da periodontite crônica é um processo contínuo que sofre períodos de exarcebação aguda através dos seguintes fatores de influência: idade; extensão da perda de inserção e óssea; profundidade da bolsa; fatores retentivos de placa; patogenicidade das bactérias colonizadas e fumo 9 . Esses fatores de influência fazem com que o prognóstico da periodontite seja determinado pela extensão, severidade e idade do paciente, podendo ser modificada por fumo, estresse e doenças sistêmicas como diabetes e HIV positivo 9,11.

A periodontite crônica é o tipo de periodontite que ocorre com maior freqüência, não ataca igualmente, somente alguns indivíduos e dentes específicos sofrem destruição avançada 10 . O problema reside diante do fato de que o exame clínico de uma gengivite ou uma periodontite leve não precisa a evolução para os quadros mais avançados da doença ${ }^{10}$. Inclusive, o levantamento epidemiológico das condições de saúde bucal da população brasileira em 2002-2003 12 revela que a porcentagem de pessoas sem nenhum problema periodontal nas faixas etárias de 15 a 19 anos, 35 a 44 e 65 a 74 anos de idade foi, respectivamente, 46,2\%, 21,9\% e 7,9\%. Já em relação à doença periodontal severa (bolsas periodontais acima de $4 \mathrm{~mm}$ ), a porcentagem de doença presente foi de 1,3\%, 9,9\% e 6,3\% nas faixas etárias de 15 a 19 anos, 35 a 44 e 65 a 74 anos 12. Ressalta-se que a baixa prevalência de doença periodontal severa na última faixa etária ocorreu porque mais de $80 \%$ dos sextantes examinados foram excluídos, devido a não apresentação de nenhum dente presente ou de apenas um dente funcional, pois nesta população $74 \%$ eram desdentados totais na arcada superior e $58 \%$ na inferior 12 .

O controle dessa doença é de extrema importância, pois além das perdas dentárias, nos últimos anos, surgiu uma nova área de pesquisa periodontal chamada de "medicina periodontal”, em que têm sido identificadas associações e evidências epidemiológicas de que as infecções periodontais possuem conseqüências sistêmicas, principalmente em doenças cardiovasculares/cerebrovasculares, nascimentos prematuros, nascimento de crianças com baixo peso, restrição do crescimento fetal e no controle glicêmico da diabetes 10,13.

Como os portadores de periodontite crônica compreendem a doença? Quais os mecanismos de autocuidado realizados? Por que os serviços especializados em Periodontia foram procurados? Na busca de responder esses questionamentos, contribuir para a adesão consciente ao tratamento e desenvolver o autocuidado aos pacientes crônicos, este estudo está sendo proposto.

\section{Metodologia}

Neste trabalho foi utilizada a abordagem metodológica qualitativa. Prova disso é que no que se refere à escolha do grupo para observação e para comunicação direta, buscou-se abranger a totalidade do problema investigado em suas múltiplas dimensões, decidindo intencionalmente os sujeitos entrevistados, não sendo, portanto, determinado antes do primeiro contato $14,15,16,17$. Para isso, os informantes-chave foram selecionados a partir da presença da pesquisadora na dinâmica 
de atendimento nas clínicas e no contato prévio com os alunos de especialização utilizando-se os seguintes critérios: pacientes portadores de periodontite crônica em tratamento e que apresentam história passada da doença.

Para triangulação dos dados e reconstrução do discurso popular, no período de outubro de 2004 a janeiro de 2005 , foram realizadas vinte entrevistas com portadores de periodontite crônica no curso de especialização de periodontia da Universidade de Fortaleza (UNIFOR) e da Associação Brasileira de Odontologia-Ceará, na cidade de Fortaleza, Ceará. Neste trabalho essa triangulação, isto é, o processo de observar um fato, um fenômeno social ou ainda uma doença a partir de vários ângulos, deu-se por meio dos relatos de "experiências vividas", das observações das atitudes e dos gestos durante as entrevistas, das fichas clínicas e sociais dos entrevistados, e discussão dos casos clínicos (dos pacientes entrevistados) com seus respectivos cirurgiões-dentistas.

A opção, nesta pesquisa, pela utilização de entrevistas semi-estruturadas não foi procedida ao acaso, mas constituiu uma opção metodológica decorrente da necessidade de maior aproximação das significações dos entrevistados, bem como, maior abertura na investigação e na relevância dos dados. As entrevistas semi-estruturadas resultam da necessidade da combinação de perguntas fechadas e abertas, em que o entrevistado tem possibilidade de discorrer e se expressar livremente, mas sem deixar de se pronunciar sobre as questões centrais que envolvem a problemática da pesquisa.

Foi elaborado um roteiro não diretivo para as entrevistas com os pacientes, em que os instrumentos eram corrigidos e readaptados durante o processo de trabalho de campo. Os aspectos principais do roteiro envolviam: dados de identificação pessoal; motivos da procura pelo serviço de periodontia; história passada e fatores causais da periodontite crônica; recursos terapêuticos e preventivos utilizados.

As entrevistas foram gravadas, transcritas, relidas e organizadas em um editor de texto. A triangulação dos dados foi utilizada para confirmar a consistência dos mesmos e validação das informações obtidas 15.

Após a leitura flutuante, exaustiva e interrogativa para impregnação de todo o material textual transcrito, foram constituídas as categorias empíricas, reelaborações e refinamento das classificações por temas. Os temas e categorias empíricas emergentes foram:

- Causas: descuido e falta de escovação, risco individual, falta de condições sócio-econômicas, os doces e alimentação em geral, fumo, germes;
- Motivação para o autocuidado: bons hábitos de higiene bucal, incentivo dos filhos, relacionamento social, vontade de realizar tratamento, consciência do autocuidado;

- Substâncias utilizadas no autocuidado: substâncias industrializadas odontológicas, substâncias industrializadas não odontológicas, plantas medicinais;

- Caráter crônico da doença: não compreensão, risco de adoecer;

- Procura pelo serviço: o que sentia para gerar a procura, incentivo social, incentivo familiar, medos, falta de dinheiro, dificuldade de acesso a serviço de periodontia.

Foi realizada a freqüência simples e percentual das principais categorias emergentes. Posteriormente, confrontou-se o material resultante coletado nesta pesquisa com o referencial teórico subjacente, a partir de uma relação dialógica tendo em vista a reflexão do empírico com o teórico e vice-versa.

As recusas e as solicitações de não gravação foram respeitadas, sendo as entrevistas nestes casos anotadas por escrito, pela própria pesquisadora. Os informantes tiveram suas identidades mantidas em sigilo e a concordância em participar da pesquisa foi afirmada por meio da assinatura do termo de consentimento livre e esclarecido. A pesquisa foi submetida à avaliação do Comitê de Ética em Pesquisa da UNIFOR, sendo aprovada em 26 de julho de 2004, e todo o material coletado está sendo utilizado somente para fins de pesquisa.

\section{Resultados}

\section{Modelo explicativo popular} da periodontite crônica

- Caso D. Madá: 50 anos, casada, 2 o grau completo, não tem filhos, fumante, possui osteoporose. Procurou o serviço devido à falta de condições de realizar o tratamento em serviço particular. Afirma ter problema na gengiva desde criança, diz que "nasceu com problema de dente, é da pessoa", antes mesmo de fumar e tomar muito café, por isso não acha que o fumo cause um agravamento da condição periodontal. Relaciona doença periodontal à falta de cálcio (devido à osteoporose) e aos dentes fracos e escuros. Confunde a cárie dentária com a doença periodontal, relacionando as fraturas dentárias e os tratamentos endodônticos realizados como causadores 
do problema no periodonto. Muito motivada desde a adolescência para a higiene bucal, mantendo sempre as visitas regulares em serviços públicos que tenham atendimento e vagas aos portadores de periodontite crônica. $\mathrm{O}$ marido briga sempre pelo excesso de creme dental consumido. Quando a gengiva está inchada e os dentes sensíveis, ela procura os serviços. É uma das duas pacientes que demonstraram ter consciência do autocuidado e não se culpa pela condição periodontal. Afirma que "tem gente que nasce com a dentição boa e outros com a ruim, não tem nada relacionado com o cuidar".

O modelo popular de explicação da "doença da gengiva", "piorréia" ou o termo científico adequado "periodontite crônica" recebe influência da tradição popular e do modelo biomédico, oscilando o discurso entre estas duas vertentes. O caso da D. Madá é bem típico para exemplificar a compreensão popular encontrada nesta pesquisa. Nas observações participantes foi identificada certa resistência dos dentistas em utilizarem o termo popular "piorréia", apesar de saberem da facilidade de compreensão para a população. Às vezes alguns entrevistados entendiam a explicação da periodontite, mas achavam que era uma doença diferente da "terrível" piorréia: "aquela que minha avó teve e perdeu todos os dentes?".

"Descuido" e "falta de escovação" são os elementos que primeiro aparecem no discurso popular quando questionados sobre a causa da periodontite crônica, sempre adicionada da des- qualificação dos hábitos bucais realizados antes da procura pelo serviço (Tabela 1). Maura, 40 anos, estudou somente até $5 \underline{a}$ serie, é muito motivada para o tratamento, viaja $150 \mathrm{Km}$ para ser atendida em Fortaleza, mas apesar do esforço, se culpa pela condição bucal: “Às vezes até a gente se descuida. Com certeza! Se tivesse cuidado melhor eu não estaria desse jeito. Se tivesse tido mais cuidado. Só que eu não tive. Aí o problema só vai se agravando".

Essa desqualificação reproduzida em seus discursos é uma repetição da fala do cirurgiãodentista durante o atendimento odontológico. Durante as observações das fichas dos pacientes entrevistados e discussão dos casos clínicos com os cirurgiões-dentistas, para a confirmação da condição periodontal, a pesquisadora enfatizava a motivação e compromisso que o paciente demonstrava em relação ao tratamento. As atitudes e falas dos profissionais seguiam um discurso semelhante, em que o esforço do paciente era desconsiderado.

Pesquisadora: “Qual a condição periodontal do paciente ' $x$ '?" [olhando as fichas e radiografias]. Cirurgião-dentista: "Muito ruim (...) muito ruim... ." Pesquisadora: "Mas ele é bem interessado (...) Demonstrou muito compromisso com o tratamento, muita dedicação...” [qualquer elogio feito]. Cirurgião-dentista: "Não, não, não (...) Ele não ajuda em nada. Sempre chega sem escovar direito !!!! Sempre tenho que brigar (...) insistir (...) dizer que ele não está fazendo direito (...) Não tem motivação !!!” Pesquisadora: "Mas não depende também do tipo

Número e porcentual dos fatores causadores da periodontite crônica relatados pelos 20 pacientes entrevistados. Fortaleza, Ceará, Brasil, 2005

\begin{tabular}{|c|c|c|}
\hline Sintomas manifestados pelos pacientes & $\mathbf{N}$ & $\%$ \\
\hline 1. Descuido/Má escovação & 10 & 19,0 \\
\hline \multicolumn{2}{|c|}{ 2. Fatores relacionados ao risco individual de adoecer (fraqueza de nascença, da estrutura física, } & 17,0 \\
\hline \multicolumn{3}{|l|}{ 3. Falta de condições socioeconômicas para o acesso a informações e aos serviços } \\
\hline odontológicos de qualidade especializados em periodontia & 9 & 17,0 \\
\hline 4. Fatores relacionados à cárie dentária/ingestão de doces e alimentos em geral & 8 & 15,0 \\
\hline 5. Fumo & 4 & 7,5 \\
\hline 6. Germes & 3 & 5,6 \\
\hline 7. Falta de tempo & 3 & 5,6 \\
\hline 8. Fatores retentivos (aparelhos ortodônticos e tártaro) & 2 & 3,8 \\
\hline 9. Uso inadequado de palito e escova & 2 & 3,8 \\
\hline 10. Estresse & 1 & 1,9 \\
\hline 11. Óleo de freio que colocou no dente & 1 & 1,9 \\
\hline 12. Empurra os dentes com a língua & 1 & 1,9 \\
\hline Total & 53 & 100,0 \\
\hline
\end{tabular}


de microorganismos da boca de cada um? Da condição sistêmica? Do estresse?”

Cirurgião-dentista: "É depende (...). mas não escova, não escova direito... ."

O diálogo acima, como vários que aconteceram durante a pesquisa, em que foi observada incompreensão dos fatores crônicos da doença, impaciência dos alunos em relação à qualidade da escovação realizada pelos pacientes e frustração devido às sessões infindáveis de raspagens com resultados pífios. E a vontade demonstrada era de "ficar livre" do paciente e dar alta. O que mantinha a distância entre a vontade e atitude eram os princípios éticos que a maioria parecia ter.

Houve alguns relatos relacionados ao risco individual de adoecer, devido à recorrência dos tratamentos realizados, que são: (a) "problema de sangue" e "estrutura óssea fraca", a chamada "fraqueza de nascença"; (b) "problema de família” (herança familiar); (c) falta de cálcio; e (d) excesso de antibiótico (Tabela 1). Vânia, 31 anos, nível médio completo, teve os quatro dentes anteriores superiores e inferiores extraídos ainda jovem, porque estavam todos amolecendo, "extraiu e pronto, lá não tinha tratamento de piorréia"; devido à sua história, explica a periodontite como "hereditária, eu acho que isso tem a ver com família (...) é como lhe falei o sangue”. Sr. Miguel, 40 anos, nível médio completo, relata muitas idas ao dentista: "se eles tivessem feito um negócio mais apurado, não teria causado tanto problema" e buscou a compreensão da doença nos antibióticos e na falta de cálcio: "Quando era criança e que vem a tomar um certo tipo de remédio, antibiótico (...) ele causa um certo efeito (...) fica mais fraco, é falta de cálcio".

Apesar de me esforçar tanto na higiene bucal, por que nunca está bom quando vou ao dentista? As explicações para o risco individual de adoecer são importantes para responder essa pergunta, entender a dificuldade de compreensão do caráter crônico da periodontite e manter o elevado grau de motivação, pois sem elas, a vontade de cuidar dos dentes tenderia a diminuir. Essa motivação é aguçada pela necessidade social (relacionamento interpessoal no trabalho, na família e entre os amigos) e pela referência positiva aos filhos.

Apesar de afirmarem que a periodontite crônica resulta de descuido e falta de escovação e remeterem também ao risco individual, o discurso é controverso, pois descrevem sessões infindáveis de escovações, do uso do fio dental, da utilização de bochechos de água morna com sal, colutórios, pedra umes (alumina de potássio), bicarbonato de sódio, malva (Malva sylvestris), aroeira (Schinus terebinthifolius Raddi), ameixa (Ximenia coriacea Engl.) para aliviar os momentos de agudização da doença, mas terminam sempre realizando a auto-responsabilização e reproduzindo o discurso biomédico: "é má escovação".

Apesar do conhecimento que demonstravam, quando os pacientes tinham dúvidas em relação às orientações do cirurgião-dentista procuravam a pesquisadora, que estava na sala de espera, para tirar dúvidas: "Como é mesmo essa escova interdental que o Dr. disse que comprasse?", "Como é o nome daquela pasta para os dentes sensiveis?”. Os momentos de conversa eram muito reduzidos durante o atendimento clínico, o que dificultava a interação com o profissional, por isso a pesquisadora esclarecia numa linguagem mais simples, desenhava a escova, colocava os nomes dos produtos indicados etc.

Em meio a uma má escovação e outra, o discurso popular relaciona a periodontite crônica à falta de condições sócio-econômicas para acesso às informações e aos serviços odontológicos de qualidade em periodontia (Tabela 1). Conseguem fugir do discurso hegemônico de má escovação e ampliar a explicação do processo saúde-doença para além de bocas, gengivas e bactérias, para incluir as condições de vida e o acesso aos serviços especializados, diferenciando, inclusive, o tratamento de periodontia como de melhor qualidade do que a simples "limpeza" realizada nos postos de saúde. E enfatizavam sempre a procura pelas clínicas nos cursos de pós-graduação pela falta de condições sócio-econômicas de freqüentar um consultório particular de qualidade: " $E$ caro!!! Dentista barato no centro da cidade está cheio, mas não é bom como os daqui!". As fichas sociais analisadas dos pacientes confirmaram o baixo poder aquisitivo dos entrevistados, em que $80 \%$ ganhavam até dois salários mínimos.

"A sociedade hoje ainda não tem muito acesso, tem um acesso muito precário. O acesso que eu tinha era precário. Os serviços eram muito rápidos..." (Frederico, 38 anos, nível médio completo, fumante, muito motivado para o uso de escova e fio dental).

"Porque tirar o tártaro, eu já tinha tirado outras vezes, quando a gente vai fazer uma limpeza é diferente de um tratamento de periodontia" (Amélia, 44 anos, nível superior incompleto, fumante, conhecia todos os anti-sépticos bucais do mercado).

Em seguida, surgem como fatores etiológicos: os doces e a alimentação em geral, fumo, os germes, falta de tempo e outros (Tabela 1). Nilson, 35 anos, nível médio incompleto, ex-alcoolista, fumante, diz que a motivação para o autocuidado é recente, depois que parou de beber. A bebida quase destruiu a sua vida e sua saúde, não comia, só bebia e fumava, por isso relacionou a periodontite ao fumo e à alimentação: “Acho que 
foi excesso de cigarro. Eu fumo muito. O fumo é porque todo dentista fala que o fumo causa (...) Como eu tenho retração e o cigarro tem muita substância química lógico que se instala lá (...) Eu acho que a alimentação, porque como ela é uma doença interna, ela também pode estar ligada com a alimentação".

Não há clareza da distinção entre a doença cárie dentária e a periodontite crônica, havendo uma constante confusão entre a etiologia destas duas doenças. A "sujeira" (biofilme dentário) e o cálculo dentário são conseqüências da má higiene e do acúmulo de alimentos na cavidade oral, como na explicação de Vânia, 31 anos: “Começa com uma carizinha, aí não vai logo ao dentista, aí vai aumentando, vai aumentando. E eu acho que tem alguma coisinha a ver porque a cárie vai corroendo, o dente vai corroendo até chegar no colo, na raiz, a gengiva pode ficar mais sensivel, inchada, inflamada. O segredo de tudo é a higiene, o segredo de tudo é a higiene dental".

Os microorganismos são explicados, não como uma infecção na cavidade bucal por patogênicos específicos, que atuam no desenvolvimento de toda doença, mas como uma atuação específica na mobilidade dentária, sendo este o sinal clínico de maior preocupação e gerador de procura por um tratamento periodontal. $\mathrm{Ou}$ seja, a procura pelo serviço odontológico é acelerada pelo terror ocasionado pela mobilidade: "Vou perder meus dentes", quando a doença está no estágio bem avançado, pois neste momento os "germes" estão presentes. Sr. Pontes, 44 anos, ensino médio incompleto, muito motivado, não entende por que não fica bom do problema da gengiva, "porque eu estou escovando tanto (...) $e$ usando o fio dental", e relaciona a periodontite aos germes. "O germe penetra nas gengivas, éaqui nos dentes. Então os dentes vão amolecendo, porque você vê que ele penetra, quando ele penetra aquela placa amarela, vai penetrando, cada vez mais os dentes. Vão ficando o quê? Amolecendo! Vai ficando mole e se perde o dente".

Somente quatro pacientes $(20 \%)$ procuraram o serviço para realizar "tratamento dentário" devido à dor de dente e fratura, e durante a triagem, foi identificada a necessidade de tratamento periodontal. Os demais 16 pacientes entrevistados (80\%) já chegaram aos serviços buscando o tratamento periodontal, sendo que para $14(70 \%)$ a indicação foi realizada por cirurgiões-dentistas e/ou serviços odontológicos. Esses encaminhamentos aos serviços especializados realizados por cirurgiões-dentistas legitimam o conhecimento prévio que os pacientes demonstraram em relação à doença.

Por possuírem uma longa história com a periodontite crônica, foi fácil a descrição dos sintomas mais presentes: sangramento, dentes moles, tártaro, gengiva inflamada, mau hálito, dente sensível e retração gengival. E o sangramento gengival, apesar de ser identificado como um dos sintomas mais presentes na periodontite crônica, muitas vezes não gera por si a procura pelo tratamento periodontal (Tabela 2).

Tabela 2

Número e porcentual dos sintomas de periodontite crônica relatados pelos vinte pacientes entrevistados. Fortaleza, Ceará, Brasil, 2005.

\begin{tabular}{lcc}
\hline Sintomas & N & $\%$ \\
\hline 1. Sangramento & 14 & 35,0 \\
2. Dente mole/dente afastando & 7 & 17,5 \\
3. Tártaro (dente amarelo) & 6 & 15,0 \\
4. Gengiva inchada & 5 & 12,5 \\
$\quad$ (vermelha/inflamada) & 3 & 7,5 \\
5. Mau hálito & 3 & 7,5 \\
6. Dente sensível & & \\
$\quad$ (até com o vento dói) & 2 & 5,0 \\
7. Retração gengival & & \\
$\quad$ (gengiva subindo) & 40 & 100,0 \\
Total & & \\
\hline
\end{tabular}

“A minha gengiva sangrava muito. Às vezes eu conversando e ela começava a sangrar. Às vezes quando eu acordava de noite já tava botando sangue. E meus dentes começaram amolecer. Aí fiquei com medo e fui pro dentista" (Maura, 40 anos).

A compreensão dos pacientes entrevistados é resultante de muitos anos de convivência com a etnoenfermidade "piorréia" e do agravamento dos seus sinais clínicos, vivenciados ao longo da vida e enraizada na cultura popular local.

\section{Discussão}

\section{Modelo explicativo popular versus modelo explicativo científico}

O modelo explicativo biomédico odontológico, dialogado nessa discussão, está fortemente construído pelo paradigma científico da profissão e foi respaldado nas observações participantes durante o atendimento clínico e nos estudos anteriores 1,18. Segundo Nuto et al. 19, a Odontologia científica avançou no conhecimento técnico-científico, mas a comunicação com o saber 
popular deixa muito a desejar, permanecendo os cirurgiões-dentistas presos ao modelo antropocêntrico, em detrimento de uma visão sistêmica da realidade. Por isso, a base de construção desse modelo, neste artigo, foi a literatura científica especializada em periodontia.

Durante a confrontação do modelo popular com biomédico odontológico 9,10,11 sobre a periodontite crônica (Tabela 3), foi identificada a pluralidade e múltiplas explicações do saber empírico em relação às explicações singulares do conhecimento científico e técnico.

Enquanto para a Odontologia a maioria das periodontites são inflamações crônicas e progressivas, caracterizadas clinicamente por perda óssea, bolsas periodontais e inflamação gengival e possuem como etiologia primária a presença de bactérias específicas residentes no biofilme dentário, associada a uma deficiência no mecanismo de defesa do paciente 9,10; para a população é "problema de gengiva" ou "piorréia" 20, causados por descuido, má escovação, falta de condições sócio-econômicas para acesso aos serviços de qualidade, doces e alimentação em geral e a presença de "germes" durante a mobilidade dentária.
Já os fatores etiológicos da periodontite crônica são confundidos com o modelo explicativo popular da cárie dentária, em que foi observado que apesar de os pacientes identificarem precocemente as cavidades cariosas, somente a dor era o fator gerador da procura por um serviço odontológico, em virtude de os "germes" ou a "lagarta" estar comendo o dente 1 . No modelo explicativo popular da periodontite crônica, a identificação do sangramento, muitas vezes não gera a procura pelo dentista, somente a mobilidade dentária, pois neste momento os "germes" estão comendo a raiz do dente. Os doces também são fatores importantes na etiologia da cárie dentária e não da periodontite crônica.

Em relação ao risco de adoecer, os pacientes estudados possuem uma explicação pluralista, respaldados pela tradição cultural, para explicar o que o modelo biomédico chama de deficiência imunológica, por meio do "problema de sangue" e estrutura óssea fraca. Ou seja, o "fraco de nascença" é a criança que desde os primeiros anos de vida é condenada a adoecer freqüentemente, devido ao desenvolvimento de problemas bucais diferentes nos membros da família, apesar de os cuidados serem semelhantes. Esse risco

Temas Modelos explicativos

Popular Biomédico odontológico

\begin{tabular}{|c|c|c|}
\hline Saber & Empírico & Científico/Técnico \\
\hline Explicações & Múltiplas/Pluralistas & Singular \\
\hline Conceitualização da periodontite crônica & "Problema de gengiva", piorréia & $\begin{array}{l}\text { Inflamações crônicas e progressivas, } \\
\text { caracteriza das clinicamente por perda óssea, } \\
\text { bolsas periodontais e inflamação gengival }\end{array}$ \\
\hline Etiologia da doença periodontal & $\begin{array}{l}\text { Descuido e má escovação; falta de } \\
\text { condições socioeconômicas; doces e } \\
\text { alimentação em geral e presença de } \\
\text { "germes" durante a mobilidade dentária }\end{array}$ & $\begin{array}{l}\text { Presença de bactérias específicas residentes } \\
\text { no biofilme dentário e deficiências no } \\
\text { mecanismo de defesa do paciente }\end{array}$ \\
\hline Procura pelo serviço odontológico & $\begin{array}{l}\text { Dentes moles ("germes" comendo a raiz), } \\
\text { sangramento, mau hálito }\end{array}$ & Início do sangramento gengival \\
\hline Risco a doença & $\begin{array}{l}\text { "Problema de sangue" e estrutura óssea } \\
\text { fraca (fraqueza de nascença), "problema } \\
\text { de família" (hereditariedade), falta de cálcio, } \\
\text { excesso de antibiótico e fumo }\end{array}$ & $\begin{array}{l}\text { Tabagismo, deficiências quantitativas e } \\
\text { qualitativas de leucócitos polimorfonucleares, } \\
\text { doenças sistêmicas como diabetes e HIV } \\
\text { positivo, estresse e padrão intrafamiliar }\end{array}$ \\
\hline Terapias utilizadas & $\begin{array}{l}\text { Substâncias naturais ou industrializadas } \\
\text { em cima do dente (água morna com sal, } \\
\text { colutórios, pedra umes, bicarbonato, } \\
\text { malva, aroeira, ameixa, cacau) e dentista } \\
\text { (periodontista) }\end{array}$ & $\begin{array}{l}\text { Remoção de placa supra e subgengival, a } \\
\text { motivação e habilidade do paciente no } \\
\text { cuidado diário, a terapia de manutenção, } \\
\text { substâncias com ação farmacológica } \\
\text { comprovada cientificamente }\end{array}$ \\
\hline
\end{tabular}


individual é relacionado aos fatores intrínsecos ao indivíduo, pois, durante toda a vida, ele sofrerá suas conseqüências, sem a possibilidade de modificações, gerando dificuldade de adesão ao autocuidado 21

$\mathrm{O}$ termo fator de risco corresponde a um aspecto de estilo de vida, ou exposição ambiental, ou uma característica inata ou inerente a uma determinada doença, respaldados por evidências epidemiológicas 10 . Os fatores de risco ou suscetibilidade à periodontite crônica são: tabagismo, deficiências quantitativas e qualitativas de leucócitos polimorfonucleares, doenças sistêmicas, como: diabetes e HIV positivo, estresse e padrão intrafamiliar 9,10,11,22. Do ponto de vista popular, além da "fraqueza de nascença" foram citados pelos pacientes: (a) "problema de família" (herança familiar), (b) falta de cálcio, (c) excesso de antibiótico e (d) fumo. Resguardadas as semelhanças entre a deficiência imunológica e a "fraqueza de nascença", o fumo e o padrão intrafamiliar também estiveram presentes nos dois modelos explicativos (científico e popular). Não existem estudos conclusivos na relação entre osteoporose e periodontite crônica 10,23.

As terapias utilizadas também variam nos dois modelos explicativos. O biomédico odontológico afirma a necessidade da remoção da placa supra e subgengival, da motivação e a habilidade do paciente no cuidado diário, da terapia de manutenção, e quando necessário, do uso de substâncias com ação farmacológica comprovada cientificamente ${ }^{10}$. A população assemelha-se ao biomédico em ressaltar a importância da ida ao dentista, especialmente um periodontista, no entanto se utiliza de substâncias naturais ou industrializadas, sem comprovação científica 20 .

Podemos identificar diferenças em relação ao saber, às explicações, à conceitualização, à etiologia, ao início da doença, à necessidade de procura pelo serviço, ao risco de adoecer e às terapias utilizadas. Já em relação aos dois modelos explicativos, notamos estilos de comunicação diferenciados, sendo a linguagem simbólica dos pacientes mantida pela transmissão oral ou gestual, intermediada e influenciada pelo discurso biomédico, enquanto a dos periodontistas é respaldada pelo conhecimento científico moderno 20 .

\section{Considerações finais}

Os portadores de doenças crônicas necessitam conhecer sua doença e aprender a conviver com ela, minimizando os efeitos causados, por meio de uma adesão consciente ao tratamento 24 . A partir dos resultados da pesquisa, foram realiza- das as seguintes considerações ao tratamento do portador de periodontite crônica:

- Conscientizar o paciente portador de periodontite crônica nos seus estágios iniciais e dos fatores de risco envolvidos no agravamento da doença. O enfoque das atividades educativas não pode estar centrado somente na "má higiene bucal”, mas agrupando todos os fatores envolvidos, para não gerar frustração na motivação para o autocuidado;

- Aproximar a linguagem e etiologia popular ao conhecimento científico, desenvolvendo, inclusive, hipóteses de risco baseadas na etnoetiologia para futuras pesquisas na área de periodontia;

- Esclarecer e divulgar o caráter crônico da periodontite, diminuindo os fatores geradores de ansiedade causados pelo prognóstico e evolução da doença;

- Realizar o tratamento do paciente com periodontite crônica por uma equipe multiprofissional, e não somente pelo cirurgião-dentista, pois este profissional sozinho não supre todas as necessidades presentes ao portador de uma doença crônica;

- Diluir o sentimento de perda e culpabilidade 25,26 do paciente diante de suas perdas dentárias, devido à responsabilização pela sua higiene bucal. Pois, por mais que o paciente dedique-se ao seu tratamento, manutenção e higiene bucal, a progressão da doença poderá ser rápida ou não estacionar, devido à sua gravidade inicial quando submetido ao tratamento e aos fatores locais, sistêmicos e/ou emocionais, ocasionando desmotivação e descrença no tratamento e no "seu dentista".

Portanto, a aproximação dos conceitos culturais e da linguagem popular em saúde, adquiridos a partir de pesquisas da área de Antropologia Médica, não garante por si, uma mudança na prática pedagógica. É preciso a superação do fosso cultural entre as instituições de saúde e a população, a compreensão da diversidade e da heterogeneidade da realidade social e da complexidade e singularidade da subjetividade humana, por meio do desenvolvimento da autonomia e da capacidade de superação das pessoas no enfrentamento das situações de saúde-doença, tanto em nível individual quanto coletivo 27. 


\section{Resumo}

Este artigo teve como objetivo analisar concepções, crenças, atitudes e modelos explicativos para a doença em portadores de periodontite crônica, visando a colaborar na comunicação clínica entre cirurgiões-dentistas e pacientes, e contribuir para a adesão consciente ao tratamento. A amostra da pesquisa constou de vinte pacientes provenientes dos cursos de especialização em periodontia da Universidade de Fortaleza e da Associação Brasileira de Odontologia, em Fortaleza, Ceará, Brasil. A coleta de dados deu-se no período de outubro de 2004 a janeiro de 2005. Referencial metodológico qualitativo foi utilizado para a interpretação da subjetividade dos pacientes. Entrevistas semi-estruturadas foram realizadas no intuito de obter relatos de "experiências vividas" dos doentes. Para a análise temática do discurso, empregaram-se: as categorias empíricas constituídas no próprio estudo, as freqüências simples e os percentuais calculados e o refinamento das classificações por temas. A partir dos relatos examinados, foi possivel analisar que os pacientes compreendem o processo saúde-doença periodontal por meio da intermediação do conhecimento popular e científico, do envolvimento das condições de vida e de trabalho e do acesso ao serviço de qualidade, ou seja, eles não incorporam somente o discurso biomédico.

Periodontite; Autocuidado; Educação em Saúde; Pesquisa Qualitativa

\section{Referências}

1. Nations M, Nuto S. "Tooth worms", poverty tattoos and dental care conflicts in Northeast Brazil. Soc Sci Med 2002; 54:229-44.

2. Nations M, Monte C. I'm not dog, no! Cries of resistance against cholera control campaigns. Soc Sci Med 1996; 43:1007-24.

3. Nations M, Misago C, Fonseca W, Correia L, Campbell O. Women's hidden transcripts about abortion in Brazil. Soc Sci Med 1997; 14:1833-45.

4. Kleinman A. Patients and healers in the context of culture. Berkeley: University of California Press; 1980.

5. Helman CG. Cultura, saúde e doença. 2a Ed. Porto Alegre: Editora Artes Médicas; 1994.

6. Ferreira J. Semiologia do corpo. In: Leal OF, organizador. Corpo e significado: ensaios de antropologia social. Porto Alegre: Editora da Universidade Federal do Rio Grande do Sul; 1995. p. 89-104.

\section{Colaboradores}

S. A. S. Nuto participou da elaboração do projeto de pesquisa, trabalho de campo, análise dos resultados e redação final. I. C. C. Costa participou da elaboração do projeto de pesquisa, análise dos resultados e revisão final do texto. M. K. Nations participou da análise dos resultados e revisão final do texto.
7. Nations MK, Camino LA, Walker FB. "Hidden" popular illness in primary care: resident's recognition and clinical implications. Cult Med Psychiatry 1985; 9:223-40.

8. Santos C, Sebastiani R. Acompanhamento psicológico à pessoa portadora de doença crônica. In: Angerami VA, organizador. E a psicologia entrou no hospital. São Paulo: Editora Pioneira; 1996. p. 147-76.

9. Flemmig TF. Periodontitis. Ann Periodontol 1999; 4:32-7.

10. Lindhe J, Karring T, Lang NP. Tratado de periodontia clínica e implantodontia oral. 4a Ed. Rio de Janeiro: Editora Guanabara Koogan; 2005.

11. Lindhe J, Ranney R, Lamster I, Charles A, Chung $\mathrm{CP}$, Flemmig T, et al. Consensus report: chronic periodontitis. Ann Periodontol 1999; 4:38. 
12. Ministério da Saúde. Projeto SB Brasil 2003: condições de saúde bucal da população brasileira 20022003: resultados principais. Brasília: Ministério da Saúde; 2004.

13. Zina LG, Moimaz SAS, Saliba NA, Garbin CAS. Periodontite materna e parto prematuro: aspectos biológicos, epidemiológicos e preventivos. Periodontia 2005; 15:10-5.

14. Minayo MC, Deslandes SF, Cruz Neto O, Gomes R, organizadores. Pesquisa social: teoria, método e criatividade. 4a Ed. Petrópolis: Editora Vozes; 1995.

15. Minayo MC. O desafio do conhecimento: pesquisa qualitativa em saúde. 4a Ed. São Paulo: Editora Hucitec; 1996.

16. Thiollent MJM. Crítica metodológica, investigação social e enquete operária. 5a Ed. São Paulo: Editora Polis; 1987.

17. Triviños A. Introdução à pesquisa em ciências sociais: a pesquisa qualitativa em educação. São Paulo: Editora Atlas; 1987.

18. Moreira TP, Nuto SAS, Nations MK. Confrontação cultural entre cirurgiões-dentistas e a experiência de usuários de baixa renda em Fortaleza, Ceará. Saúde Debate 2004; 28:58-67.

19. Nuto SAS, Nations MK, Albuquerque SHC, Costa ICC. O saber popular em odontologia e o processo saúde-doença. In: Dias AA, organizador. Saúde bucal coletiva: metodologia de trabalho e práticas. São Paulo: Editora Santos; 2006. p. 119-37.
20. Nuto SAS, Costa ICC, Nations MK. Motivação do autocuidado na periodontite crônica: um estudo qualitativo. Periodontia 2006; 16:76-82.

21. Nuto SAS, Nations MK. O que é cárie dentária? Conflitos entre as percepções populares e profissionais. Rev ABO Nac 2002; X:184-7.

22. Corrêa DS, Costa FO, Zenóbio EG, Barbosa FI, Cunha FA. Padrão intrafamiliar da doença periodontal: distribuição e análise das variáveis de risco sociais e comportamentais. Periodontia 2005; 15:30-8.

23. Nonaka CFW, Nascimento GJF, Galvão HC, Freitas RA. Osteoporose e doença periodontal - revisão dos aspectos atuais. Periodontia 2005; 15:46-52.

24. Rabelo SL, Padilha MICS. Compreensão dos déficits de autocuidado a partir da prática assistencial. Texto \& Contexto Enfermagem 2000; 9:312-23.

25. Ryan W. Blaming the victim. New York: Pantheon Books; 1971.

26. Valla V, Stotz E, organizadores. Participação popular, educação e saúde: teoria e prática. 2a Ed. Rio de Janeiro: Editora Relume-Dumará; 1993.

27. Vasconcelos EM. Educação popular e a atenção à saúde da família. 2a Ed. São Paulo: Editora Hucitec/Sobral: Edições UVA; 2001.

Recebido em 16/Fev/2006

Versão final reapresentada em 19/Jun/2006

Aprovado em 26/Jul/2006 